\title{
Publication Opportunity in the Journal of Psychopathology and Behavioral Assessment
}

\author{
Randall T. Salekin
}

Published online: 12 February 2011

(C) Springer Science+Business Media, LLC 2011

This issue marks the beginning of the third year and volume of Journal of Psychopathology and Behavioral Assessment. The journal remains committed to the presentation of key developments in the science and practice of psychopathology and assessment, broadly conceived. As the journal has progressed, there has been new knowledge put forth on the general psychometric properties of existing measures. Moreover, new measures have been developed and introduced to the broader community of psychologists and mental health professionals via the journal. A great deal of knowledge has been acquired on psychopathology, assessment and its treatment. All of these studies have provided rich journal content.

The journal remains dedicated to promoting the dissemination of knowledge of diverse facets of the profession of psychopathology and assessment. The journal is also committed to research on the treatment of psychopathology and especially articles that pertain to the measurement of change (i. e., reductions in psychopathology). It remains a goal of the journal to reflect the mastery of the assessment, psychopathology, and treatment areas for which authors are studying. In order to continue the flow of high quality manuscripts that have been submitted to the journal, I highlight several issues that I am hopeful will remain an important focus of the journal.

\section{Scope of the Journal: Multi-Dimensional Perspective}

The journal is committed to accepting research articles from a variety of theoretical perspectives. This is because we believe that this is the best way to acquire knowledge in psychology. Therefore, manuscripts from varying perspec-

\section{R. T. Salekin $(\triangle)$}

Disruptive Behavior Clinic, Department of Psychology,

University of Alabama,

P.O. Box 870348, Tuscaloosa, AL 35487, USA

e-mail: rsalekin@bama.ua.edu tives (e.g., behavioral, cognitive, developmental, genetic, humanistic, positive psychology, psychoanalytic) will best help inform the profession about current conceptualizations of psychopathology, its assessment, and treatment. Whether individually or collectively, I hope this wide range of articles will help us better understand human functioning. Like the developmental psychopathology paradigm, the journal will hopefully serve to include relevant research on psychopathology form a variety of theoretical orientations.

\section{Time Perspective: Single Time Point and Longitudinal} Research

In my initial editorial (Salekin 2009), I stressed the importance of single time point research for establishing nomologinal nets, but also challenged researchers to examine disorders across time. This remains an important agenda item for the journal and I continue to encourage authors to highlight measurement of psychopathology across time. By doing so, researchers will be able to note both the risk and protective factors that might be at play in bringing about the onset of disorders, or factors that protect against their development. Investigations of the mediators or potential causes of disorders are also important and best captured in longitudinal designs. Research that focuses on typical development, longitudinally, will also be welcomed as these manuscripts will shed light on what factors contribute to well being and will help in efforts to reduce mental illness in our communities.

\section{Sources of Information}

Much more research is needed on the variations that can occur across sources of information as well as across measures. That there are discrepancies can be cause for 
concern especially if two self-report indices are attempting to tap the same construct and produce low agreement. Important knowledge can come from discovering differences across sources and measures. A return to multimethod assessment could help us better understand both pathological and healthy development. Fortunately, research has been revived in this area, and it is my hope that the Journal of Psychopathology and Behavioral Assessment will serve a critical outlet for this type of research.

\section{Biology: Genetics, Brain Function and Structure}

In my first editorial (Salekin 2009), I noted the importance of research on genetics, behavioral genetics, fMRI research and the need to better integrate biology into the assessment of psychopathology and its treatment. I continue to see these as important growth areas. There is also a need for close monitoring of both the mental and behavioral changes that are being made in individuals while conducting the biological aspects of the research. Combining biological methods with the close monitoring of individual functioning through innovative techniques (e.g., smart phones) will shed more light on psychopathology and its development and amelioration. Measurement that is sensitive to the changes in individuals across time and interventions will be key.

\section{Special Sections}

Two important special sections appeared since the inception of the journal. One was edited by our Associate Editor Carl F. Weems and the other by Associate Editor Jennifer L. Tackett. Dr Weems' special section was on the importance of emotion regulation as a construct, its' measurement, and the implications of this construct in the field of psychopathology and assessment (Weems and Pina 2010). Dr. Tackett's special section focused on personality development in youth and how understanding personality development in this population can help to bridge our understanding of psychopathology in youth (Tackett 2010).

\section{Closing Comments}

There are major benefits of relying on broad input to help determine the range of topics, contribution, and foci of the journal. Consequently, I welcome suggestions for articles, special sections, or special issues, and programs of research. The journals diverse content allows for a unique combination of articles ranging from psychopathology to assessment. The links between the two and how assessment methodology might help us better understand the etiology of disorders is needed. Moreover, how these two topics relate to prevention and intervention strategies is needed.

In closing, the Journal of Psychopathology and Behavioral Assessment is unique in that it is one of the only journals that cover both psychopathology and assessment, as well as the interventions that help us understand pathology and positive change. Thus, authors can be assured that as the impact of the journal continues to rise, a large audience will receive their articles. In addition, the review process we make every effort to provide prompt, thorough, and constructive comments. I am very thankful for the work of the two Associate Editors of the Journal, Jennifer Tackett and Carl Weems who have worked diligently to make the journal a success. I am also very grateful to the editorial board whom have consistently provided authors with excellent reviews that are both thoughtful and constructive in their content and nature. The same can be said for our ad hoc reviewers and as such, I want to publically thank them for their service to the journal. Without this service to the journal we would not be able to reach such a high level of scholarship. Finally, I thank the authors that have contributed excellent manuscripts to the journal. I also encourage those who are new to consider the journal as an outlet for their research. I look forward to seeing the journal grow and the opportunity to see future excellent scholarship cross my desk in the promising next years of the journal.

\section{References}

Salekin, R. T. (2009). Psychopathology and assessment: contributing knowledge to science and practice. Journal of Psychopathology and Behavioral Assessment, 31, 1-6.

Tackett, J. L. (2010). Measurement and assessment of child and adolescent personality pathology: introduction to the special section. Journal of Psychopathology and Behavioral Assessment, 32, 463-466.

Weems, C. F., \& Pina, A. A. (2010). The assessment of emotion regulation: improving construct validity in research on psychopathology in youth - an introduction to the special section. Journal of Psychopathology and Behavioral Assessment, 32, 17. 